\title{
Study on Start-Up Process of SAGD by Solvent: Experiment Research and Process Design
}

\author{
Jun Sun (iD, Yanping Sun, Chengsheng Wang, Hui Lin, Wenchao Zhou, Yunchuan Fu, \\ and Shuliang Ren
}

CNOOC EnerTech-Drillinge Production Co., Tianjin 300452, China

Correspondence should be addressed to Jun Sun; sunjun2@cnooc.com.cn

Received 13 March 2021; Accepted 3 June 2021; Published 21 June 2021

Academic Editor: Xiaofei Sun

Copyright (c) 2021 Jun Sun et al. This is an open access article distributed under the Creative Commons Attribution License, which permits unrestricted use, distribution, and reproduction in any medium, provided the original work is properly cited.

\begin{abstract}
Steam-assisted gravity drainage (SAGD) has been used to develop the "super heavy" oil reservoirs in Canada. The viscosity can reach more than $30,000 \mathrm{cp}$ at $50^{\circ} \mathrm{C}$. Moreover, owing to their continental deposit origin, the reservoirs have a low porosity and permeability. Because of these challenges, the conventional steam circulation start-up process takes 6 to 12 months before the well pair can be switched to production. Solvent has been used to start-up SAGD with success. But now, low price of oil and high cost of solvent make solvent-assisted start-up process limited. This paper applies experimental schemes, such as viscosity reduction rate evaluation, core flooding, and $3 \mathrm{D}$ physical simulation, tests solvent performance, optimizes process parameters, and designs process solutions. Apply numerical simulation to test solvent-assisted SAGD start-up effect and calculate the cost. This paper researches a unique low-cost solvent compare with xylene. The basic properties and core flood experiment show that the two solvents are similar with viscosity reduction rate, asphalt dissolution rate, and injection pressure, and the price of solvent is $18 \%$ lower. The 3D model experiment shows that the average start-up time is reduced by $15 \%$, and steam injection volume is reduced by $21.4 \%$. The numerical simulation results show that without solvent, it will take $180 \mathrm{~d}$ for start-up process, and with solvent, the time has reduced by $50 \%$ and takes 90 days. Cost calculation results show that the cost will reduce $18 \%$ by solvent compared to xylene. Moreover, the production rate has been improved in production stage. This paper applies a 3D physical model to simulate the solvent-assisted SAGD start-up process. Research conclusions show the start-up mechanism of solvent and the process of temperature change of steam chamber.
\end{abstract}

\section{Introduction}

Oil sands of NEXEN are rich in reserves and good reservoir properties, suitable for SAGD technology development. By the end of 2015, there were 121 production wells in 15 PADs, and the average single well production that has been put into production is $60 \sim 70 \mathrm{~m}^{3} / \mathrm{d}$. The gasoline ratio is $4-5$, high recovery rate [1-3]. However, at present, the cost of SAGD development of barrel oil is about 70 US dollars. In the case of low oil prices, the high-cost problem is prominent [4]. On the other hand, low-yield and low-efficiency wells account for about one-third of the total, resulting in unsatisfactory development of oil sands [5].

This paper takes Longlake oil sand in southwest Canada as the target block. The average recoverable thickness of the reser- voir is $27.8 \mathrm{~m}$, effective porosity is $32.2 \%$, and oil saturation is $71.7 \%$. The horizontal permeability is $5.94 \mu \mathrm{m}^{2}$, and the vertical permeability is $4.74 \mu \mathrm{m}^{2}$. The reservoir temperature is $6-8^{\circ} \mathrm{C}$, the pressure is $750-950 \mathrm{kPa}$, and the crude oil viscosity is $6 \times 10^{7} \mathrm{cp}$ at $10^{\circ} \mathrm{C}$. It is a typical oil sand reservoir in Canada.

This paper takes the SAGD start-up phase as a research entry point, and physical simulation and numerical simulation studies were carried out for a series of problems such as less oil production, large steam consumption, low energy utilization rate, and difficulty in handling the produced liquid during the SAGD warm-up start-up process. By adopting the solvent composite steam cycle method [6-8], the cycle of SAGD start-up phase is shortened, the steam injection amount is reduced, the mining cost is reduced, and the mining efficiency is improved [9-11]. 


\section{Physical Model Experimental Study}

Physical simulation experiments include injection performance studies and 3D physics simulation experiments.

The injection performance includes the following: application of one-dimensional physical simulation device (Figure 1), system injection capability experiment, injection capacity change experiment after solvent injection to water flooding, and influence of injection speed on injection capacity. Through the injection performance study, the injection performance of the solvent and the effect on the steam cycle after solvent injection are analyzed to provide theoretical data for the process scheme.

The three-dimensional physical simulation experiment (Figure 2) compares the steam cycle with the solvent+steam cycle two kinds of preheating methods to analyze the effect of adding solvent to the steam cycle preheating. Verify the feasibility of solvent-assisted SAGD fast start technology.

A sand pipe of $30 \mathrm{~cm}$ long and $2.5 \mathrm{~cm}$ diameter was filled with river sand, and three groups were filled, with a permeability of $6000 \mathrm{mD}$ and a porosity of $32 \%$. The filled sand filling tube was vacuumed, saturated water and saturated oil were injected into water, solvent and xylene were at a rate of $0.5 \mathrm{~mL} / \mathrm{min}$, and the changes of injection pressure of the three systems were analyzed (Figure 3 ).

This paper compares the three system injection capabilities, and the pressure of the breakthrough sand pipe model of xylene is the lowest, indicating that the injection performance of xylene is the best, and the breakthrough pressure of solvent and xylene is not much different. The injection performance of the two is equivalent, far better than the water. Injection performance: after the breakthrough of xylene and solvent system, the injection pressure decreased rapidly, indicating that the seepage channel was formed in the model, and the injection pressure in the simple water injection process was slow, indicating that the water seepage ability in the model was very poor after the water injection broke the model.

The one-dimensional model was filled in the same way, and the solvent was injected at a rate of $0.5 \mathrm{~mL} / \mathrm{min}$. After the pressure was broken, the water flooding was started, and the change of the injection pressure was analyzed. As shown in Figure 4, after the solvent breakthrough, the water flooding did not increase significantly, indicating that the solvent breakthrough exceeded the formation of the seepage channel, which significantly increased the injection capacity of the subsequent water flooding.

Three groups of one-dimensional models were filled in the same way, and solvent hydrocarbons were injected at a rate of $0.1 \mathrm{~mL} / \mathrm{min}, 0.3 \mathrm{~mL} / \mathrm{min}$, and $0.5 \mathrm{~mL} / \mathrm{min}$ to analyze the change of the injection pressure difference. As shown in Figure 5, as the injection speed increases, the breakthrough pressure increases. When the speed is $0.5 \mathrm{~mL} / \mathrm{min}$, the breakthrough pressure is $13 \mathrm{MPa}$. When the speed is $0.3 \mathrm{~mL} / \mathrm{min}$, the breakthrough pressure is $10 \mathrm{MPa}$ and the velocity is 0.1 $\mathrm{mL} / \mathrm{min}$, and the breakthrough pressure is $4 \mathrm{MPa}$. As the injection speed increases, the breakthrough time decreases. When the speed is $0.5 \mathrm{~mL} / \mathrm{min}$, the breakthrough time is 58 $\min$. When the speed is $0.3 \mathrm{~mL} / \mathrm{min}$, the breakthrough time is $76 \mathrm{~min}$. When the speed is $0.1 \mathrm{~mL} / \mathrm{min}$, the breakthrough time is $210 \mathrm{~min}$. Once the solvent breaks through the model, the pressure is immediately reduced by less than $1 \mathrm{MPa}$, indicating that the percolation channel is established inside the model by injecting the solvent, which greatly reduces the injection pressure.

This paper is a detailed study of SAGD 3D physics simulation experiment, and a three-dimensional proportional physical model simulating the field of the oil field was established in the experiment. The key to physical simulation is the similarity between experimental physical models and oilfield reservoir prototypes. The degree of similarity between the experimental physical model and the reservoir prototype is an important criterion for the success of the simulation experiment. Therefore, physical simulation experiments must follow the similarity criterion theory. In the SAGD experimental physical model, the effects of gravity and thermal effects on the recovery of heavy oil are mainly considered. The experimental physical model was designed based on the similarity criteria, and the SAGD initiation experimental parameters were calculated, as shown in Table 1.

The SAGD physical simulation experiment flow is shown in Figure 6. The three-dimensional model has a size of $\varphi 40$ $\times 40 \mathrm{~cm}$ and 351 temperature test points inside to realize real-time monitoring of the temperature field. The threedimensional physical simulation of SAGD is to arrange double horizontal wells at the bottom of the model. The horizontal well length is $30 \mathrm{~cm}$, and the horizontal well spacing is $10 \mathrm{~cm}$. A row of 5 temperature measuring points is distributed in the middle of the double horizontal wells. Parallel to the horizontal wells, the temperature of different positions of the horizontal wells is measured. Field changes: horizontal wells are connected to the steam generator to achieve steam injection and circulation. This experiment is the start-up phase of SAGD. The experimental content is the steam injection cycle to heat the horizontal well oil layer, and the steam cycle start time and period are calculated by the temperature field change. The effect of preinjection solvent on steam cycle time and steam volume was verified by comparing the temperature field changes between the individual steam cycle and the solvent+steam cycle.

Comparison of the time required for the temperature rise between the two horizontal wells to $80^{\circ} \mathrm{C}$ is shown in Table 2, and the effect of the preinjection solvent on the steam injection cycle time of SAGD is obvious. The steam cycle time required to reach $80^{\circ} \mathrm{C}$ in the middle of the injectionproduction well is greatly reduced. The cycle of the horizontal well injection end is reduced by $42.86 \%$, the horizontal well tip position is reduced by $6.25 \%$, and the full horizontal section is reduced by $15 \%$. The closer to the injection end, the more obvious the decrease. By calculating the cycle time variation, it can be concluded that the steam injection amount can be reduced by $21.4 \%$, achieving the purpose of saving steam injection cost.

Through the changes of the temperature field of the injection wellbore in Figures 7 and 8, it can be seen that the preinjection solvent starts to change the heating rate of the steam-filled injection well. The steam cycle is 1 hour, the solvent+steam circulation injection well can reach $70^{\circ} \mathrm{C}$, the steam cycle is used alone, and the temperature between the 


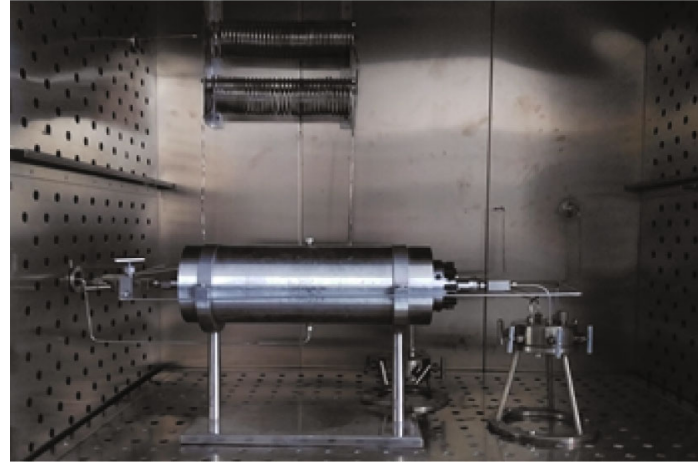

FIgURE 1: One-dimensional physical simulation device.

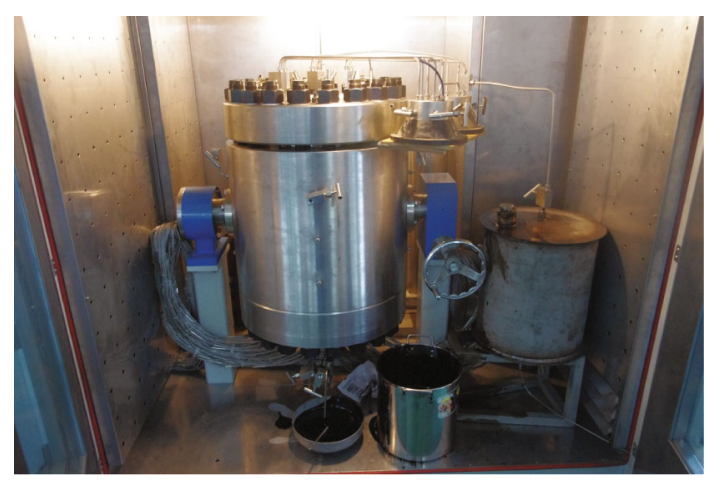

Figure 2: Three-dimensional physical simulation device.

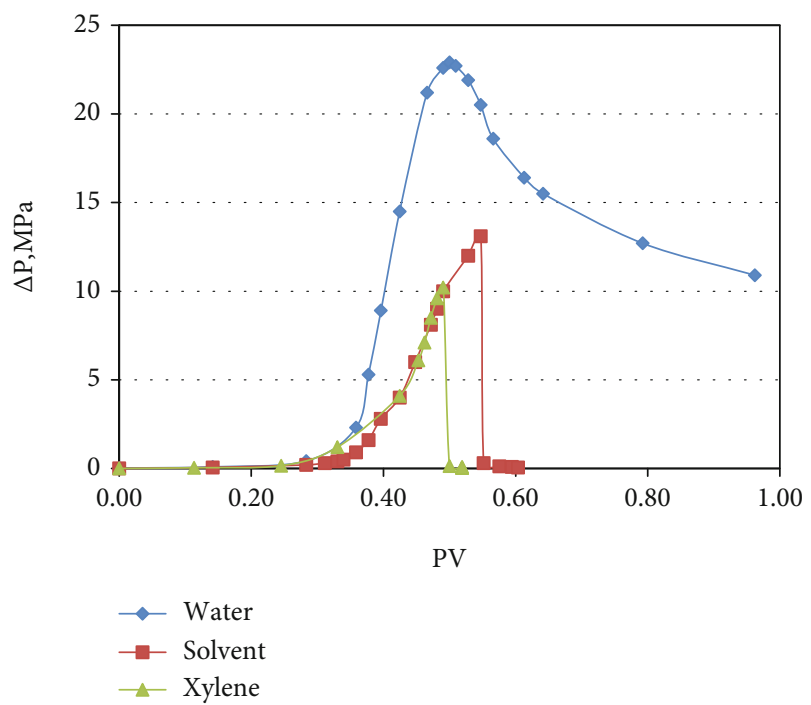

FIgURE 3: Comparison of three system injection capabilities.

injection and production wells is $40^{\circ} \mathrm{C}$. The steam cycle is 3 hours, the solvent+steam circulation injection well can reach $80^{\circ} \mathrm{C}$, the steam cycle is used alone, and the temperature between the injection and production wells is $70^{\circ} \mathrm{C}$. The steam cycle is 7 hours, the solvent+steam circulation injection well can reach $95^{\circ} \mathrm{C}$, the steam cycle is used alone, and the temperature between the injection and production wells

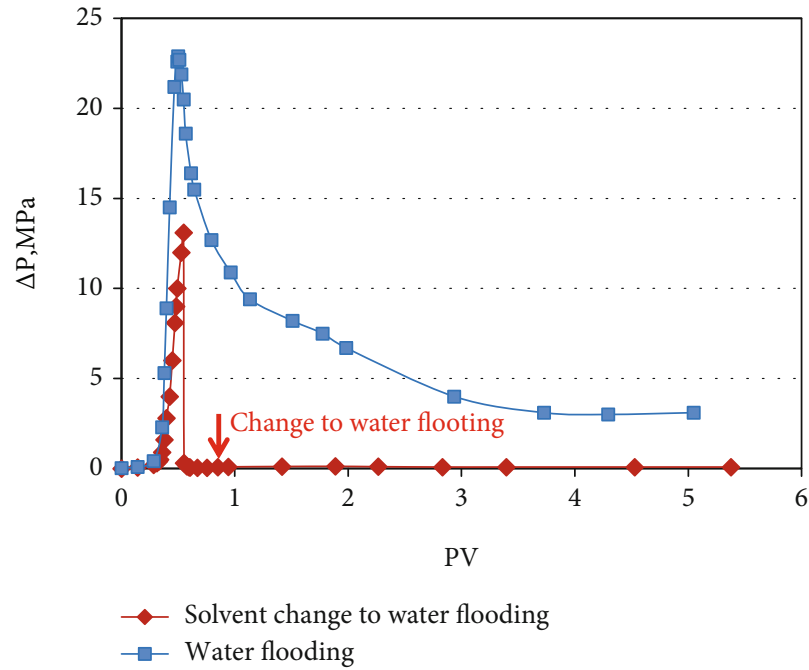

FIGURE 4: Injection pressure comparison of water and solvent to water.

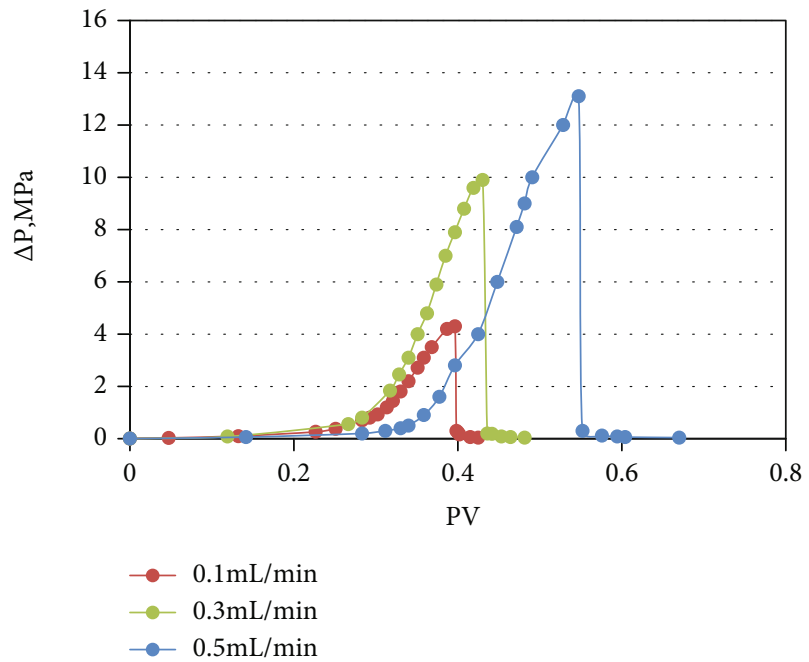

FIGURE 5: Effect of injection speed on injection pressure.

is $80^{\circ} \mathrm{C}$. The solvent-assisted SAGD start-up mode increases the start-up rate and improves steam utilization efficiency.

The injection capacity of the solvent is higher than that of the water flooding. After the solvent is transferred to the water flooding, the seepage channel formed by the solvent can improve the seepage capacity of the water phase and increase the heat convection capability of the steam and the reservoir. The higher the solvent injection speed, the stronger the injection capacity. In the constant pressure injection experiment, the higher the pressure, the stronger the solvent injection capacity. It indicates that the greater the pressure of the on-site solvent injection process, the stronger the solvent entry ability. The steam injection time required to reach $80^{\circ} \mathrm{C}$ in the middle of the injection-production well is analyzed. The effect of the preinjection solvent on the temperature is obvious, the average cycle time of the full-level section is reduced by $15 \%$, and the steam injection amount can be reduced by $21.4 \%$. The results of comprehensive physical simulation studies show that the solvent has a stronger 
TABLE 1: 3D model experimental parameters.

\begin{tabular}{lccc}
\hline Parameters & Data & Parameters & Data \\
\hline Total capacity $/ \mathrm{L}$ & 50.3 & Initial water content of model $/ \mathrm{L}$ & 2.35 \\
Pore volume $/ \mathrm{L}$ & 18.8 & Original oil saturation $/ \%$ & 87.5 \\
Porosity $/ \%$ & 37.5 & Original oil in place $/ \mathrm{L}$ & 16.5 \\
Horizontal permeability $/ \mathrm{mD}$ & 6000 & Steam injection speed $/\left(\mathrm{mL} \cdot \mathrm{min}^{-1}\right)$ & 10 \\
Vertical permeability $/ \mathrm{mD}$ & 6000 & Steam injection temperature $/{ }^{\circ} \mathrm{C}$ & 300 \\
Model temperature $/{ }^{\circ} \mathrm{C}$ & 30 & Well type & Double horizontal well \\
Irreducible water saturation $/ \%$ & 12.5 & Well spacing $/ \mathrm{cm}$ & 10 \\
\hline
\end{tabular}

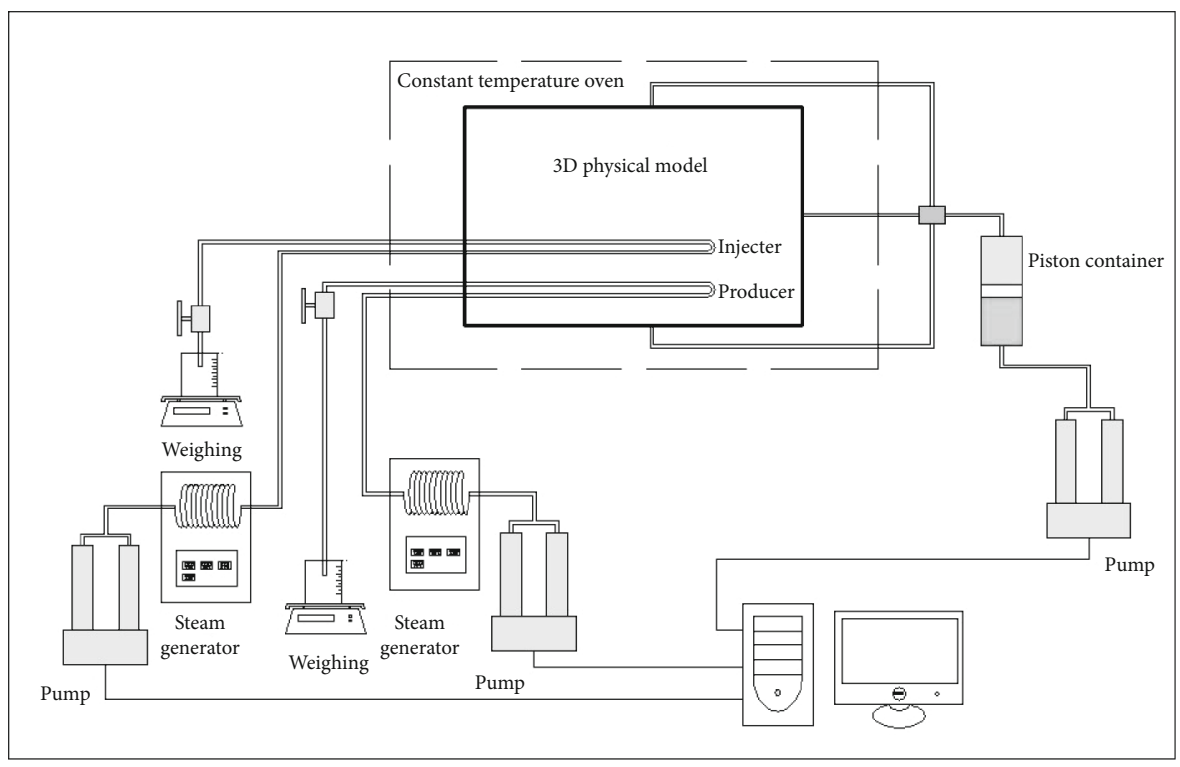

FIGURE 6: Schematic diagram of SAGD physical simulation experiment.

TABLE 2: Comparison of the time required for the temperature between the two horizontal wells to rise to $80^{\circ} \mathrm{C}$.

\begin{tabular}{|c|c|c|c|c|c|}
\hline Temperature test point number & 1 & 2 & 3 & 4 & 5 \\
\hline Distance from the injection, $\mathrm{cm}$ & 6 & 12 & 18 & 24 & 30 \\
\hline Steam cycle time, $\mathrm{h}$ & 7 & 4.5 & 6 & 7 & 8 \\
\hline Solvent+steam cycle time, $\mathrm{h}$ & 4 & 3.5 & 5 & 6 & 7.5 \\
\hline Cycle time reduction, $\%$ & 42.86 & 22.22 & 16.67 & 14.29 & 6.25 \\
\hline Average cycle time reduction, $\%$ & & & 15 & & \\
\hline Steam injection reduction, $\%$ & & & 21.4 & & \\
\hline
\end{tabular}

injection capacity than water, and after being injected into the oil sands reservoir, it can be miscible with the oil sands, reducing the viscosity of the oil sands, making steam and oil sands. The enhanced thermal convection is more conducive to heat transfer between steam and oil sands. At the same time, the heat transfer between the subsequent steam and the oil sand is enhanced, the steam heat efficiency is improved, and the cycle is shortened.

\section{Numerical Simulation Study}

This paper studies numerical simulation for the start-up of SAGD, and the solvent-assisted SAGD quick start process scheme was designed. A numerical model was established, and numerical simulation studies were applied to analyze the effect of solvent-assisted SAGD start-up technology. The design process and process scheme are shown in Table 3 . The reservoir geological and fluid physical parameters in the numerical model are shown in Table 4.

Using the CMG numerical simulation software STARS module, oil, water vapor, and solvent are taken as independent components, respectively, and the parameters related to oil layer temperature and pressure, such as gas-liquid equilibrium constant, gas density, gas viscosity, chemical solvent density, and solvent viscosity, are input. The simulated chemical solvent assists the SAGD warm-up process. 

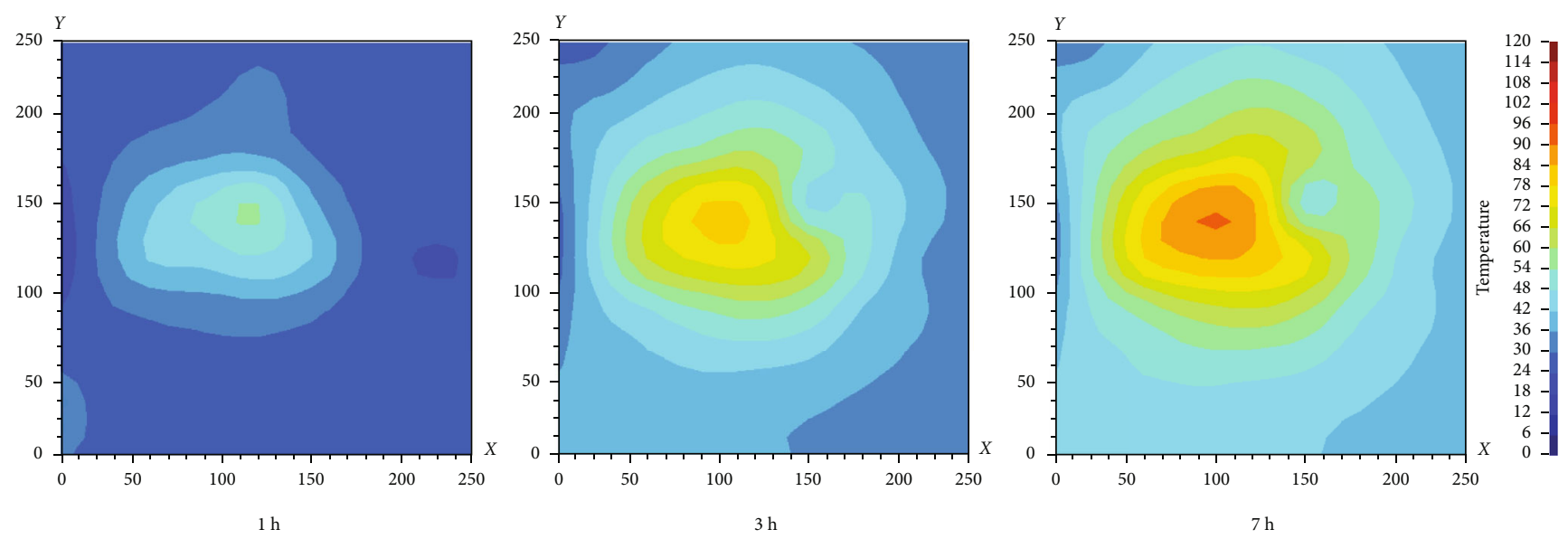

FIgURE 7: Temperature field perpendicular to the injection well profile changes with time (steam).
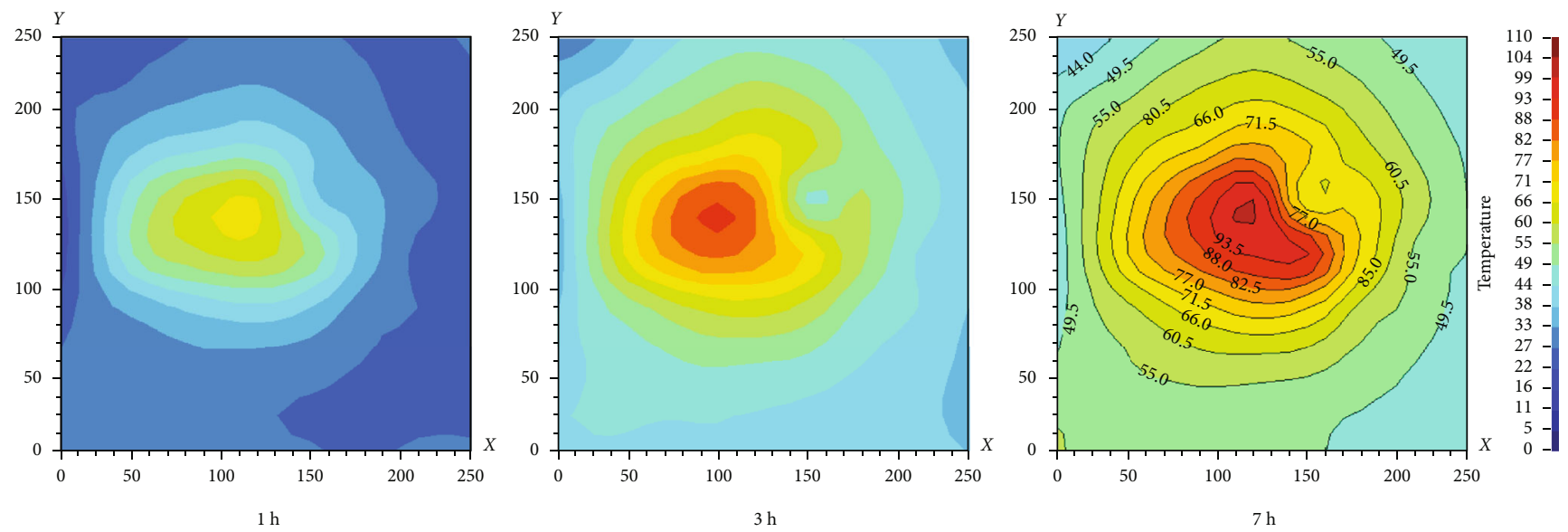

Figure 8: Temperature field perpendicular to the injection well profile changes with time (solvent+steam).

TABle 3: Comparison of the time required for the temperature between the two horizontal wells to rise to $80^{\circ} \mathrm{C}$.

\begin{tabular}{|c|c|c|}
\hline No. & Process program & Process plan \\
\hline 1 & $\begin{array}{l}\text { Steam circulation well } \\
\text { washing }\end{array}$ & $\begin{array}{c}\text { Inject steam to circulate and displace the remaining drilling fluid and washing } \\
\text { fluid in the well. The cycle time is } 1 \mathrm{~d} \text {. }\end{array}$ \\
\hline 2 & Prestage plug solvent & $\begin{array}{l}\text { Injecting wells and production wells simultaneously with } 35 \mathrm{~m}^{3} \text { of solvent at the } \\
\text { maximum allowable bottomhole pressure }\end{array}$ \\
\hline 3 & Solvent soaking & 12 days off, let the solvent soak and mix in the formation \\
\hline 4 & Steam cycle & $\begin{array}{l}\text { Bringing a fluid that can be flowed after being soaked in a solvent, the steam is further } \\
\text { circulated at a high injection amount until it can be injected into SAGD production. }\end{array}$ \\
\hline 5 & $\begin{array}{l}\text { Pre-SAGD and fluid } \\
\text { connectivity test }\end{array}$ & $\begin{array}{l}\text { Injecting steam into the well, producing wells, monitoring the bottom temperature and return } \\
\text { conditions of the production well, and determining whether the fluid between the two wells is connected }\end{array}$ \\
\hline
\end{tabular}

Simulated steam injection cycle preheating start parameters are as follows: steam cycle speed $150 \mathrm{~m}^{3} / \mathrm{d}$, preheating dryness $95 \%$, steam cycle temperature $220^{\circ} \mathrm{C}$, and solvent injection volume $35 \mathrm{~m}^{3}$; judging criteria for preheating effect are as follows: the average temperature between horizontal wells is $80^{\circ} \mathrm{C}$, and the connection rate is $75 \%$. According to the viscosity-temperature curve, the viscosity of crude oil is $1371 \mathrm{cp}$ at $80^{\circ} \mathrm{C}$ in Figure 9. The simulation starts from January 1, 2018, and compares the preheating effect of adding two kinds of chemical solvents in the double well steam cycle preheating and the double well steam cycle preheating process, as shown in Figure 10. It takes 114 days to reach $80^{\circ} \mathrm{C}$ without adding solvent, and it takes 60 days to reach $80^{\circ} \mathrm{C}$ with adding solvent. After adding solvent, the heat loss during SAGD is less than that without solvent. 
TABLE 4: Reservoir geology and fluid physical parameters.

Parameter

Numerical value

Reservoir top depth (m) 243

Effective thickness (m)

Initial reservoir temperature $\left({ }^{\circ} \mathrm{C}\right)$ 7

Rock compressibility $(1 / \mathrm{kPa})$

$7.0 \times 10^{-6}$

Specific heat capacity $\left(\mathrm{J} /\left(\mathrm{m}^{3} \cdot{ }^{\circ} \mathrm{C}\right)\right)$

$2.04 \times 10^{6}$

Thermal conductivity of rock $\left(\mathrm{J} /\left(\mathrm{m} \cdot \mathrm{day} \cdot{ }^{\circ} \mathrm{C}\right)\right)$

$4.60 \times 10^{5}$

Thermal conductivity of oil $\left(\mathrm{J} /\left(\mathrm{m} \cdot \mathrm{day} \cdot{ }^{\circ} \mathrm{C}\right)\right)$

$1.18 \times 10^{4}$

Thermal conductivity of gas $\left(\mathrm{J} /\left(\mathrm{m} \cdot \mathrm{day} \cdot{ }^{\circ} \mathrm{C}\right)\right)$

$4.0 \times 10^{3}$

Thermal conductivity of water $\left(\mathrm{J} /\left(\mathrm{m} \cdot\right.\right.$ day $\left.\left.\cdot{ }^{\circ} \mathrm{C}\right)\right)$

$5.35 \times 10^{4}$

Thermal conductivity of upper and lower caprocks $\left(\mathrm{J} /\left(\mathrm{m} \cdot \mathrm{day} \cdot{ }^{\circ} \mathrm{C}\right)\right)$

$4.6 \times 10^{5}$

Heat capacity of upper and lower caprocks $\left(\mathrm{J} /\left(\mathrm{m}^{3} \cdot{ }^{\circ} \mathrm{C}\right)\right)$

$2.04 \times 10^{6}$

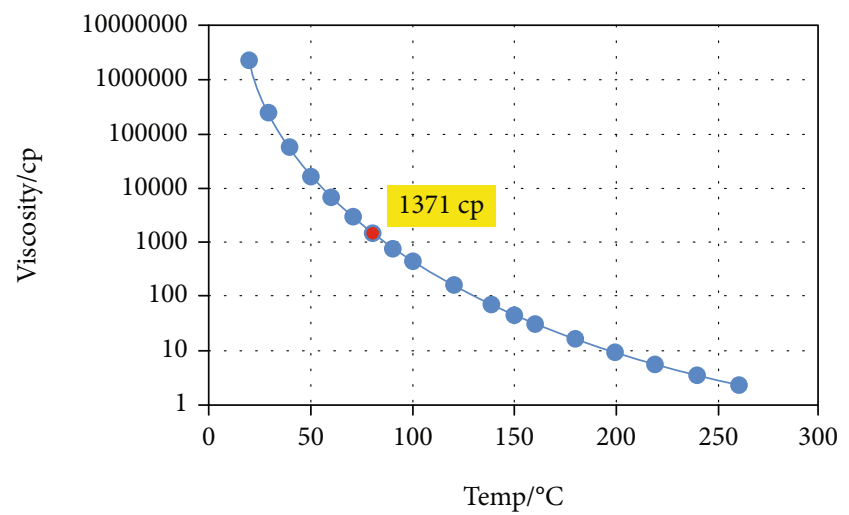

FIGURE 9: Viscosity-temperature curve of oil sand.

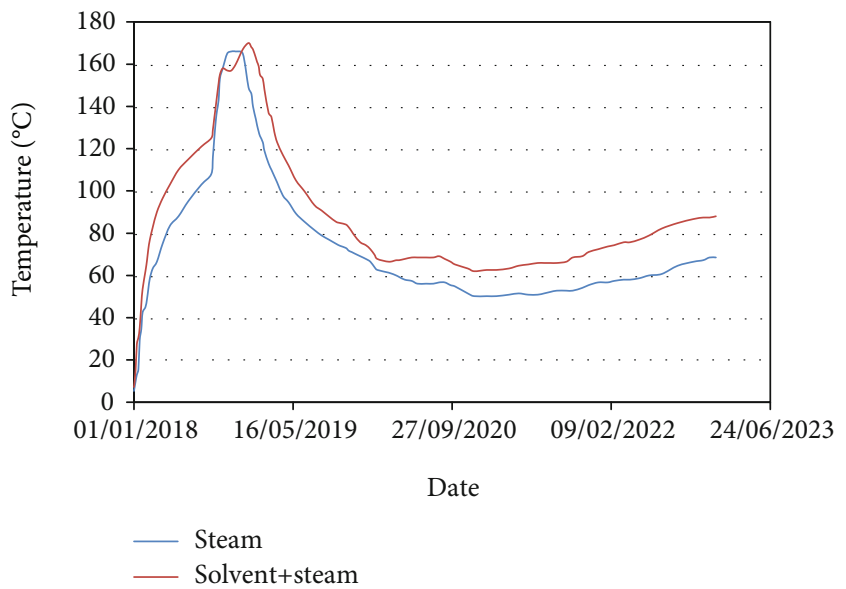

FIGURE 10: Interwell temperature change during SAGD production.

\section{Conclusions}

The injection capacity of the solvent is higher than that of the water flooding. After the solvent is transferred to the water flooding, the seepage channel formed by the solvent can improve the seepage capacity of the water phase. The higher the solvent injection speed, the stronger the injection capacity. In the constant pressure immersion experiment, the higher the pressure, the stronger the solvent injection capacity.

The prestage plug is injected into the solvent+steam circulation mode, which is $15 \%$ shorter than the single steam cycle start-up period, and the steam injection amount can be reduced by $21.4 \%$. The solvent is injected into the formation, dissolves the oil sand to reduce the viscosity, enhances the heat conduction and heat convection between the steam and the formation, and achieves the purpose of shortening the cycle period.

It takes $114 \mathrm{~d}$ to reach $80^{\circ} \mathrm{C}$ without adding solvent, and $60 \mathrm{~d}$ is needed with adding solvent. After the addition of the solvent, the start-up time was reduced by $47 \%$. The numerical simulation results are consistent with the physical model results, indicating that the solvent can effectively reduce the steam cycle and improve the steam efficiency.

\section{Data Availability}

The data are available on request.

\section{Conflicts of Interest}

The authors declare that they have no conflicts of interest.

\section{Acknowledgments}

The authors would like to thank the management of CNOOC EnerTech-Drilling\&Production Co. for allowing the publication of this paper. Sincere thanks are also owed to many others, in particular, the physical simulation experiment researcher whose diligence has made the work a success.

\section{References}

[1] S. Chen, S. Dou, H. You, and W. Guo, "SAGD recycle preheating technology to doublehorizontal well and field application," Xinjiang Oil ఓGas, vol. 8, pp. 6-10, 2012.

[2] Y. Ji, L. Cheng, Z. Liu, and Q. C. Liu, "Experiment of injecting non-condensable gas during SAGD process to improve 
development performance," Journal of Southwest Petroleum University, Science \& Technology Edition, vol. 32, no. 2, pp. 108-112, 2010.

[3] J. Pang, "A review of the development of Canadian oil sands," Petroleum Planning and Engineering, vol. 24, no. 4, pp. 5-8, 2013.

[4] Y. Chen and H. Liu, "The mining status and technology improvements of oil sand," Petrochemical Industry Application, vol. 30, no. 3, pp. 4-7, 2011.

[5] X. Zhang, X. Zheng, D. J. Tai, and M. H. Meng, "The technical research on adding none condensate gas in SAGD," Journal of Southwest Petroleum University: Science \& Technology Edition, vol. 32, no. 2, pp. 113-117, 2010.

[6] A. A. Alturki, I. D. Gates, and B. B. Maini, "Co-injection of noncondensable gas improves ES-SAGD performance in shallow oil sands reservoirs with a small top water zone," in CSUG/SPE, Calgary, Alberta, Canada, 2010.

[7] W. Q. Li and D. D. Mamora, "Numerical simulation of thermal solvent replacing steam under steam assisted gravity drainage (SAGD) process," in SPE Western Regional Meeting, Anaheim, California, USA, 2010.

[8] T. N. Nasr, D. H. S. Law, and H. Golbeck, "Counter-current aspect of the SAGD process," JCPT, vol. 39, no. 1, pp. 41-47, 2000.

[9] T. P. Wellman, R. B. Grigg, B. J. McPherson, R. K. Svec, and P. C. Lichtner, "Evaluation of CO2-brine-reservoir rock interaction with laboratory flow tests and reactive transport modeling," in International symposium on oilfield chemistry. Society of Petroleum Engineers, Houston, Texas, 2003.

[10] F. A. Qazvini and F. Torabi, "Feasibility study of solvent-based huff-n-puff method (cyclic solvent injection) to enhance heavy oil recovery," in SPE heavy oil conference Canada, Calgary, Alberta, Canada, 2012.

[11] R. M. Butler and I. J. Mokrys, "Solvent analog model of steamassisted gravity drainage," AOSTRA Journal of Research, vol. 5, no. 1, pp. 17-32, 1989. 